\title{
Rat mesenchymal stem cells differentiate to endothelial cells after allotransplantation into the damaged nerve
}

\author{
E.S. Petrova*, E.N. Isaeva and D.E. Korzhevskii \\ Department of General and Special Morphology, Institute of Experimental Medicine, St. Petersburg, Russia
}

\begin{abstract}
At present, achievements in regenerative neurobiology have demonstrated that transplantation of different kinds of stem cells can have a stimulating effect on the processes of reparative regeneration of the nervous system. The experimental elaboration of mesenchymal stem cells (MSCs) transplantation to stimulate nerve regeneration is carried out actively. There is evidence that MSCs promote the growth of the recipient regenerating axons after transplantation into the damaged nerve or a conduit. However, the fate of the transplanted cells and their differentiation is poorly studied. The aim of the present study was to investigate localization and differentiation of rat bone marrow MSCs 1 and 7 days after transplantation into the injured sciatic nerve of adult rats. MSCs from Wistar-Kyoto rats were cultured for 7 days and labeled with BrdU 3 days prior to usage. The sciatic nerve of adult Wistar-Kyoto rats was pinched and a suspension of BrdU-labeled cultured MSCs was immediately transplanted into a damaged sciatic nerve. 1 day after surgery, the transplanted MSCs were found in the endoneurium. 7 days after transplantation, the MSCs were found survive and were localized in the epineurium. A part of the transplanted MSCs differentiates to cells of the vessel wall; according to their morphology, these were endothelial cells. Thus, the transplanted MSCs can contribute to regeneration of the transected nerve by involvement in vascularization of the injured tissue.
\end{abstract}

\section{Introduction}

Current regenerative neurobiology have demonstrated that transplantation of stem cells can have a stimulating effect on the processes of reparative regeneration of the nervous system organs [13]. The experimental elaboration of cellular technologies to stimulate nerve regeneration is carried out actively [4-7]. There is evidence that the mesenchymal stem cells (MSCs) promote the growth of the recipient regenerating axons after transplantation into the damaged nerve or a conduit [8-10].

Current research on nerve regeneration is generally performed on mesenchymal stem cells derived from bone marrow, adipose tissue, umbilical cord stroma, amniotic fluid and other tissues [10, 11]. The choice of bone marrow or fat tissue is guided by the fact that they provide an easy access and are autologous sources of stem cells for transplantation therapies. In addition, MSCs have the capacity to modulate immune responses [12]. The possible adverse effects of cell therapy have been discussed [9,13-15]. The negative consequences include host immune response to non-self stem cells, tumor development, inflammation, connective tissue scar formation, etc. In this regard, the study of the fate of the transplanted cells and their differentiation takes on particular relevance. The aim of the present study was to investigate localization and differentiation of rat bone marrow MSCs 7 days after transplantation into the injured sciatic nerve of adult rats.

\section{Material and methods}

\section{MSCs}

MSCs derived from bone marrow of Wistar-Kyoto rats were provided by-“Trans-Technologies" (Russia). The method of obtaining and characteristics of MSCs were described in more detail earlier by Zinkova et al. [3]. Cells were cultured for a week, using a culture flasks
(NEST Scientific, USA) and culture medium MEM alpha (BioloT, Russia) supplemented with bovine serum. Three days prior to usage of culture, 5-bromo-2-deoxyuridine (BrdU) (Sigma, USA) was added to the medium. The MSCs suspension was washed twice with the medium without BrdU and centrifuged for $15 \mathrm{~min}(200 \mathrm{~g})$. The precipitate was resuspended in $1 \mathrm{ml}$ of fresh medium, and viability of the cells was tested using $0.2 \%$ trypan blue solution (BioloT, Russia) and by cell calculation in a Goryaev chamber. The cell suspension was used for transplantation if the viability of the latter was at least $90 \%$.

\section{Experimental procedures}

Adult male Wistar-Kyoto rats were used $(n=20)$; their housing and all experiments were carried out according to the rules for work with experimental animals. The research was positively approved by the local Ethics Committee of the Institute of Experimental Medicine, (St. Petersburg, Russia). The sciatic nerves of recipient rats were lesioned by application of a ligature for $40 \mathrm{~s}$ at the level of the upper third of the thigh. A small section ( $1 \mathrm{~mm}$ long) of epineural and perineural sheaths was made close to the site of the lesion. At this site, a cell suspension ( 5 $\times 10^{4}$ in $5 \mu \mathrm{l}$ medium) was infused under the perineurium of the nerve trunk by a thin glass cannula $(0.6 \mathrm{~mm}$ in diameter). The surgery was conducted under an MBS-2 microscope (LOMO, Russia) under aseptic conditions. The method of transplantation of MSCs were described in more detail earlier [16]. Then, the animals were kept in standard

Correspondence to: E.S. Petrova, Department of General and Special Morphology, Institute of Experimental Medicine, St. Petersburg, Russia, E-mail: iemmorphol@yandex.ru

Key words: allograft, 5-bromo-2-deoxyuridine (BrdU), differentiation, mesenchymal stem cells, nerve regeneration

Received: July 04, 2016; Accepted: August 02, 2016; Published: August 05, 2016 
conditions of vivarium and were killed after 1 and 7 days with overdose of ethyl ether vapor. The nerve segments containing transplant were fixed in a zinc-ethanol-formaldehyde solution [17]. After dehydration of the material in alcohols of increasing concentration and pouring in paraffin, the sections ( $5 \mu \mathrm{m}$ in thickness) were cut using rotary (RM 2125RT Leica, Germany) and mounted on silane treated (HistoBondR, Germany) glass slides. Histological preparations were stained with toluidine blue.

\section{Immunohistochemical reactions}

The transplanted mesenchymal stem cells of the graft were identified by immunohistochemical reaction to BrdU. Monoclonal antibody to BrdU (Bu20a clone, Dako, Denmark, at a dilution 1: 100 were used. Reagents from the EnVision+System Labeled Polymer HRP AntiMouse (K4001) kit (Dako, Denmark) were used as secondary reagents. The preparations were investigated in microscope «Leica» (Leica, Germany) and photographed with Leica ICC 50 digital camera (Leica) operated by LAS EZ software (ver. 1.8.0, Leica Microsystems, Switzerland).

\section{Results and discussion}

Toluidine blue staining of the MSCs revealed their morphological features (Figure 1a). We succeeded to obtain image in Figure 1a owing to adhesiveness, a characteristic property of the MSCs in culture: the MSCs were fixed and stained just in the cell culture flasks. These are fibroblast-like cells with processes and rounded or oval nucleus. One or two nucleoli are distinctly visible in the nucleus. These morphological characteristics of the MSCs are in full accordance with those described by other authors $[3,8,10]$.

For transplantation, a suspension of the cultured cells was made. To check the BrdU uptake into MSCs, smears were prepared from the suspension and BrdU immunohistochemistry was carried out on the smears. Analysis of immunohistochemical preparations showed BrdU in most MSCs: the brown-colored nucleus indicated the BrdU uptake into the cell (Figure 1b). Therefore, after transplantation of BrdUlabeled MSCs beneath the perineurium of sciatic nerve, they can easily be distinguished from the recipient cells 1 and 7 days later.

A day after ligation of the sciatic nerve and transplantation of MSCs, the sciatic nerve of the recipient rats was almost unchanged. Light microscopy showed only slight swelling of some nerve fibers and enlargement of some blood vessels. Figure 1c demonstrates grafted BrdU-labeled cells scattered among the nerve fibers in the endoneurium of the recipient. Generally, they have oval nucleus containing BrdU. Accumulations of BrdUimmunopositive cells were seen in the endoneurium near the site of injury of the nerve and injection of the MSCs suspension. In the epineural sheath, the BrdU-labeled cells were not found.
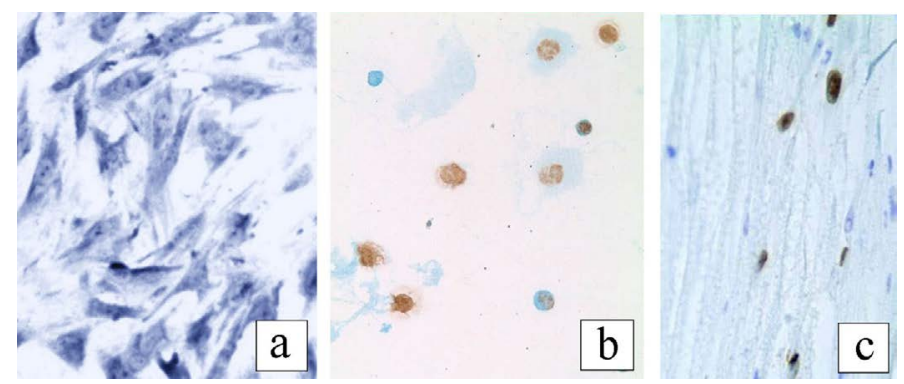

Figure 1. MSCs in culture $(a)$, BrdU-containing MSCs in a smear $(b)$ and in the sciatic nerve 1 day after transplantation (c) ( $a$ - toluidine blue staining, $b, c-\operatorname{BrdU}-$ immunohistochemistry $\times 400$ ).
7 days after surgery, the injured nerve fibers of recipient showed signs of Wallerian degeneration: an increased number of mononuclear cells, dilatation of blood vessels, edema of nerve fibers, and thickening of the nerve sheaths. The fragmentation of the axons and the myelin debris could not be detected because of the applied fixation and histological processing of the material. The BrdU-labeled MSCs were found in the epineurium. The transplanted cells were revealed in the wall of blood vessels and were looking like endothelial cells (Figure 2a), pericytes, or smooth muscle cells (Figure $2 \mathrm{~b}$ ). In histological preparations at high magnification, the labeled cells were looking like typical endothelial cells and were bordering the lumen of the vessel containing blood cells (Figure 3).

The present study demonstrates that the BrdU-labeled MSCs injected beneath the perineurium, a day later were found in endoneurium, while 7 days after surgery were revealed in epineurium as well. These results are the clear indication of migration of the MSCs for a week after grafting into the epineural sheath of the recipient's nerve. MSCs are known to have a high migration potential. Their migration has been described after MSCs transplantation into the brain [3]. They affect axonal regeneration after transplantation into nerve or nerve conduit (bridge nerve gap) or after intravenous administration [18]. Migration potential of MSCs results in their detection in the site of the sciatic nerve injury 7 days after the intravenous injection to mice, which enhances functional recovery of the sciatic nerve [18]. The data obtained in our study suggest that the transplanted cells enter the blood vessels of the ligated nerve through the injured vascular wall. The permeability of the walls of vasa nervorum increases as a result of processes accompanying Wallerian degeneration. It's notorious that, simultaneously with degeneration of axons and myelin sheaths, the repair of the injured nerve occur [19]. During the angiogenesis, MSCs

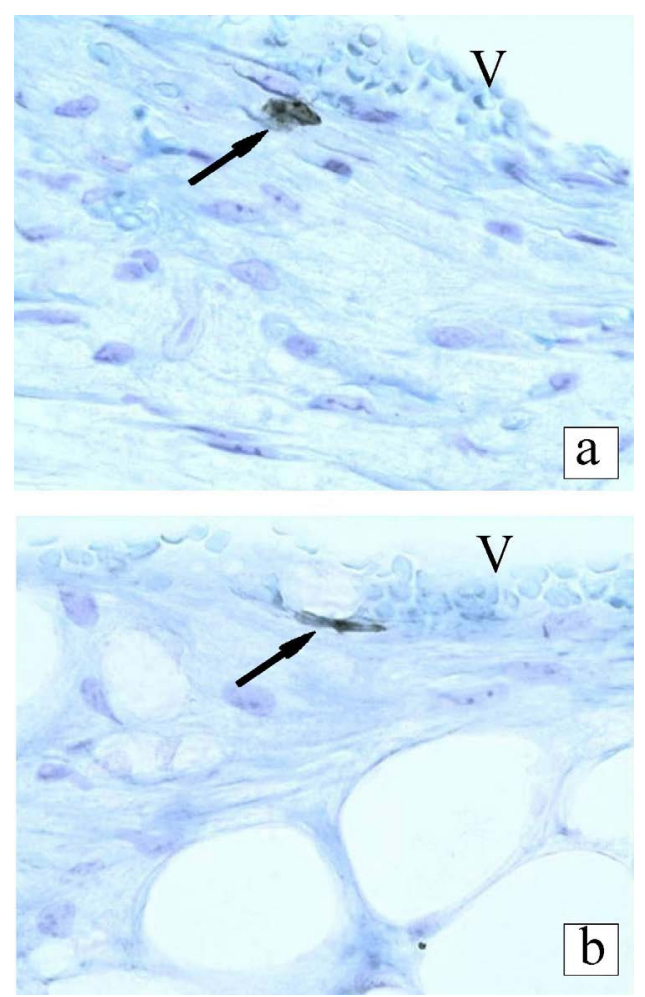

Figure 2. BrdU-labeled transplanted cells in the in recipient epineurium 7 days after transplantation in the rat sciatic nerve. V - cavity of a blood vessel (BrdUimmunohistochemistry, toluidine blue counterstaining $\times 400$ ). 


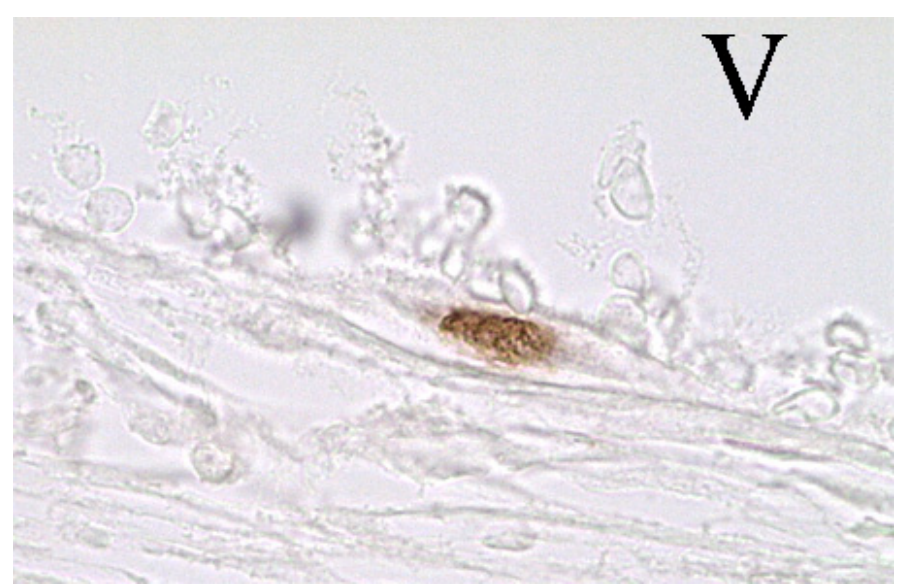

Figure 3. BrdU-labeled endothelial cell in the vessel wall of the rat sciatic nerve. V - cavity of a blood vessel $($ BrdU-immunohistochemistry $\times 1000)$.

can be integrated into the blood vessel wall.

Bone marrow MSCs were discovered by Friedenstein et al. [20, 21]. These are mesoderm-derived cells that form connective tissue throughout the body and form fibroblasts, osteoblasts, chondrocytes, adipocytes, and endothelial cells [22]. Now, it has been found that MSCs can be obtained from many adult tissues: bone marrow stromal cells, adipose tissue, dental pulp, umbilical cord blood and other tissues $[10,11]$. MSCs isolated from bone marrow stroma of mammals and humans have been shown to differentiate under certain conditions in vitro into different cell types: cardiomyocytes, astrocytes, neurons, and some other $[11,23]$. It has been shown that MSCs synthesize and secrete growth and trophic factors such as epidermal growth factor (EGF), hepatocyte growth factor (HGF), fibroblast growth factor (FGF), transforming growth factor $\beta$ growth (TGF $\beta$ ), brain-derived neurotrophic factor (BDNF), glial cell-derived neurotrophic factor (GDNF), nerve growth factor (NGF), and proteins of the extracellular matrix (collagen, fibronectin, laminin) [10,24]. Furthermore, they are immunomodulators [25], and produce anti-inflammatory cytokines and anti-apoptotic molecules [26]. Due to these properties, MSCs are often used for transplant experiments to stimulate the regeneration of the damaged nerve.

The favorable influence of MSCs on the restoration of peripheral nerves has been shown in experiments on different kinds of animals: rodents, rabbits, dogs, and primates (for review see [4, 5, 27]). Molecular and cellular mechanisms of the obtained effect require further fundamental studies. It is assumed that as secreted biologically active substances, the MSCs make a good microenvironment for growth of the recipient's axons. For example, it has been established that MSCs produce BDNF and, thus, stimulate the growth of nerve fibers [28]. Possibly, transplanted cells can differentiate into Schwann and are involved in myelination of regenerating axons.

Given the fact that researchers use MSCs from different sources for transplantation, and their administration is performed in different ways (intravenously, directly into the nerve trunks, or in conduits connecting the segments of the transected nerve and containing various excipients), the problem of differentiation of these cells after transplantation require special research in each case. In this regard, one of the most important tasks is to study the fate of the transplanted cells, their survival time and differentiation features.

The present study showed that some of the transplanted MSCs differentiate to the endothelial cells. As to differentiation to Schwann cells, there is an ambiguity in literature. Potentiality of MSCs to differentiate to Schwann cells has been demonstrated in some in vitro studies. It has been shown that the directed differentiation of MSCs to the Schwann cells can be accomplished by their co-cultivation with spinal ganglia neurons [29], or by adding to the culture medium the glial growth factor-2 [24]. However, the present study shows that, no BrdU-labeled cells were found in recipient's endoneurium 7 days following surgery. In view of this fact, it seems unlikely that the transplanted MSCs differentiate to Schwann cells.

Therefore, it remains debatable whether Schwann-like cells can derive from implanted stem cells. There is a hypothesis positing that transplanted stem cells can directly differentiate to the Schwann cells and facilitate axonal myelination [30, 31]. In contrast, most other researchers believe that differentiation to the Schwann cells cannot take place without prior in vitro transdifferentiation or predifferentiation of stem cells $[13,14,32]$. Results of the present study are in agreement with the second point of view.

Thus, the present study revealed that MSCs transplanted in the injured nerve survive for at least 7 days and differentiate to cells of vessel wall, in particular to endothelial cells of the blood vessels. Vascular supply of the peripheral nerve is extensively involved in regeneration and, thus, the transplanted MSCs can contribute to regeneration of the transected nerve by involvement in vascularization of the injured tissue.

\section{Conflict of interest statement}

The authors declare that the research was conducted in the absence of any commercial or financial relationships that could be construed as a potential conflict of interest.

\section{References}

1. Southwell DG, Nicholas CR, Basbaum AI, Stryker MP, Kriegstein AR, et al. (2014) Interneurons from embryonic development to cell-based therapy. Science 344 : 1240622. [Crossref]

2. Li Y, Hu G, Cheng Q (2015) Implantation of human umbilical cord mesenchymal stem cells for ischemic stroke: perspectives and challenges. Front Med 9: 20-29. [Crossref]

3. Zin'kova NN, Sokolova IB, Viide SK, Shvedova EV, Alexandrov GV, et al. (2007) Mesenchymal stem cell therapy of brain ischemic stroke in rats. Cell and Tissue Biology 1:389-398. [Crossref]

4. Walsh S, Midha R (2009) Use of stem cells to augment nerve injury repair Neurosurgery 65: A80-86. [Crossref]

5. Fairbairn NG, Meppelink AM, Ng-Glazier J, Randolph MA, Winograd JM1 (2015) Augmenting peripheral nerve regeneration using stem cells: A review of current opinion. World J Stem Cells 7: 11-26. [Crossref]

6. Kingham PJ, Kalbermatten DF, Mahay D, Armstrong SJ, Wiberg M, et al. (2007) Adipose-derived stem cells differentiate into a Schwann cell phenotype and promote neurite outgrowth in vitro. Exp Neurol 207: 267-274. [Crossref]

7. Masgutov RF, 2, Masgutova GA, Zhuravleva MN, Salafutdinov II, et al. (2016) Human adipose-derived stem cells stimulate neuroregeneration. Clin Exp Med 16: 451461. [Crossref]

8. Dezawa M, Takahashi I, Esaki M, Takano M, Sawada H (2001) Sciatic nerve regeneration in rats induced by transplantation of in vitro differentiated bone-marrow stromal cells. Eur J Neurosci 14: 1771-1776. [Crossref]

9. Wong RS1 (2011) Mesenchymal stem cells: angels or demons? J Biomed Biotechnol 2011: 459510. [Crossref]

10. Chen CJ, Ou YC, Liao SL, Chen WY, Chen SY, et al. (2007) Transplantation of bone marrow stromal cells for peripheral nerve repair. Exp Neurol 204: 443-453. [Crossref]

11. Kalinina NI, Sysoeva VY, Rubina KA, Parfenova YV, Tkachuk VA (2011) Mesenchymal stem cells in tissue growth and repair. Acta Naturae 3: 30-37. [Crossref] 
12. Rubtsov YP, Suzdaltseva YG, Goryunov KV, Kalinina NI, Sysoeva VY, et al. (2012) Regulation of Immunity via Multipotent Mesenchymal Stromal Cells. Acta Naturae 4 23-31. [Crossref]

13. Ladak A, Olson J, Tredget EE, Gordon T (2011) Differentiation of mesenchymal stem cells to support peripheral nerve regeneration in a rat model. Exp Neurol 228: 242-252. [Crossref]

14. Keilhoff G, Fansa H (2011) Mesenchymal stem cells for peripheral nerve regeneration-a real hope or just an empty promise? Exp Neurol 232: 110-113. [Crossref]

15. Petrova ES1 (2015) Injured Nerve Regeneration using Cell-Based Therapies: Current Challenges. Acta Naturae 7: 38-47. [Crossref]

16. Petrova ES, Isaeva EN (2014) [Effect of embryonic anlage allografts of the rat spinal cord on growth of regenerating fibers of the recipient nerve]. Izv Akad Nauk Ser Biol : 549-556. [Crossref]

17. Korzhevskii DE, Sukhorukova EG, Gilerovich EG, Petrova ES, Kirik OV, et al(2014) Advantages and disadvantages of zinc-ethanol-formaldehyde as a fixative for immunocytochemical studies and confocal laser microscopy Neurosci. Behav Physiol 44: 542-545.

18. Marconi S, Castiglione G, Turano E, Bissolotti G, Angiari S, Farinazzo A, Constantin G, Bedogni G, Bedogni A, Bonetti B (2012) Human adipose-derived mesenchymal stem cells systemically injected promote peripheral nerve regeneration in the mouse model of sciatic crush Tissue. Eng Part A 18: 1264-1272.

19. Zochodne DW (2008) Neurobiology of Peripheral Nerve Regeneration. Cambridge, New York, Melbourne, Madrid, Cape Town, Singapore, Sao Paulo: Cambridge University Press.

20. Friedenstein AJ, Piatetzky-Shapiro II, Petrakova KV (1966) Osteogenesis in transplants of bone marrow cells. J Embryol Exp Morphol 16: 381-390. [Crossref]

21. Friedenstein AJ, Chailakhyan RK, Gerasimov UV (1987) Bone marrow osteogenic stem cells: in vitro cultivation and transplantation in diffusion chambers. Cell Tissue Kinet 20: 263-272.
22. Pittenger MF, Mackay AM, Beck SC, Jaiswal RK, Douglas R, et al. (1999) Multilineage potential of adult human mesenchymal stem cells. Science 284: 143-147. [Crossref]

23. Xu FT, Li HM, Yin QS, Cui SE, Liu DL, et al. (2014) Effect of ginsenoside Rg1 on proliferation and neural phenotype differentiation of human adipose-derived stem cells in vitro. Can J Physiol Pharmacol 92: 467-475. [Crossref]

24. Brohlin M, Mahay D, Novikov LN, Terenghi G, Wiberg M, et al. (2009) Characterisation of human mesenchymal stem cells following differentiation into Schwann cell-like cells. Neurosci Res 64: 41-49. [Crossref]

25. Aggarwal S, Pittenger MF (2005) Human mesenchymal stem cells modulate allogeneic immune cell responses. Blood 105: 1815-1822. [Crossref]

26. Uccelli A, Moretta L, Pistoia V (2008) Mesenchymal stem cells in health and disease. Nat Rev Immunol 8: 726-736. [Crossref]

27. Petrova ES (2012) [The use of stem cells to stimulate regeneration of damaged nerve] Tsitologiia 54: 525-540. [Crossref]

28. Lopatina T, Kalinina N, Karagyaur M, Stambolsky D, Rubina K, et al (2011) Adiposederived stem cells stimulate regeneration of peripheral nerves: bdnf secreted by these cells promotes nerve healing and axon growth. de novo PLOS ONE 6: e17899.

29. Yang J, Lou Q, Huang R, Shen L, Chen Z (2008) Dorsal root ganglion neurons induce transdifferentiation of mesenchymal stem cells along a Schwann cell. lineage Neurosci Lett 445: 246-251.

30. Akiyama Y, Radtke C, Honmou O, Kocsis J D (2002) Remyelination of the spinal cord following intravenous delivery of bone marrow cells. Glia 39: 229-236.

31. Ravasi M, Scuteri A, Pasini S, Bossi M, Menendez VR, Maggioni D, Tredici G (2013) Undifferentiated MSCs are able to myelinate DRG neuron processes through p75 Exp Cell. Res 319: 2989-2999.

32. Tomita K, Madura T, Mantovani C, Terenghi G (2012) Differentiated adipose-derived stem cells promote myelination and enhance functional recovery in a ratmodel of chronic denervation. J Neurosci Res 90: 1392-1402.

Copyright: (2016 Petrova ES. This is an open-access article distributed under the terms of the Creative Commons Attribution License, which permits unrestricted use, distribution, and reproduction in any medium, provided the original author and source are credited. 